\title{
Application of a LabVIEW for Real-Time Control of Ball and Beam System
}

\author{
Basil Hamed
}

\begin{abstract}
Virtual instrumentation is defined as the combination of measurement and control hardware and application software with industry-standard computer technology to create user-defined instrumentation systems. This paper presents a real-time application of Ball and Beam controlled by PID controller designed based on LabVIEW program and the real - time position control of the DC motor was realized by using DAQ device. Ball and Beam is a common feedback control system application, due mostly to its ease in construction and its use in learning. Using Labview makes the application very useful for teaching and training students in data conversion domain. The system includes a ball, a beam, a motor and several sensors. The basic idea is to use the torque generated from a motor to control the position of the ball on the beam. The mathematical model for this system is inherently nonlinear, so linearization was done in order to improve the controllability of the system. Data acquisition, signal processing and analyzing can be completed by virtual instrument based on LabVIEW.
\end{abstract}

Index Terms-Ball and Beam, proportional-integralderivative (PID), Data Acquisition Card, Lab View.

\section{INTRODUCTION}

Closed loop control systems classified for two types of control, analog and digital. Analog and digital control have a relation between each other that can convert analog to digital and vice versa which gives the control world more flexibility for controlling any device. Figure 1 show the cycle of converting analog signal to digital signal and applying digital signal to computer then converting the digital signal back to analog signal.

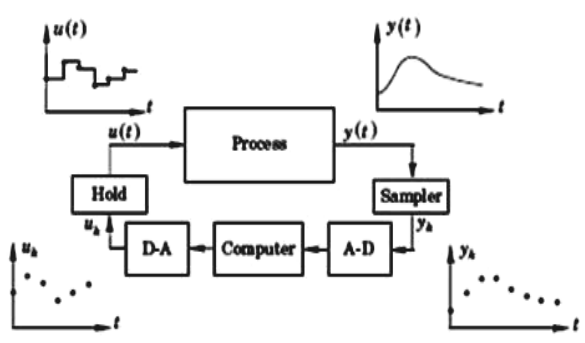

Figure (1): Cycle of analog and digital signal

Nowadays most of the applications which need more accuracy are controlled by digital control. Table (1) shows the advantages and disadvantages of the analog and digital control

Basil Hamed is with theElectrical Engineering Department, Islamic University of Gaza, P.O.BOX 108, Gaza, Palestine(email: bhamed@iugaza.edu).

\begin{tabular}{|l|l|}
\hline Digital Controller & Analog Controller \\
\hline $\begin{array}{l}\text { More expensive. } \\
\text { Flexibility in response } \\
\text { to design changes. }\end{array}$ & $\begin{array}{l}\text { 1. Less expensive. } \\
\text { Noise immunity. }\end{array}$ \\
$\begin{array}{l}\text { More accuracy. } \\
\text { bore }\end{array}$ & $\begin{array}{l}\text { More sensitive for } \\
\text { noise. }\end{array}$ \\
& 4. Less accuracy. \\
\hline
\end{tabular}

TABLE (1): ADVANTAGES AND DISADVANTAGES; OF ANALOG AND DIGITAL CONTROLLERS.

The Ball and Beam is a common feedback control system, due mostly to its ease in construction, and its use in learning for applying control to stabilize an unstable system. This system is extremely unstable and needs compensation to stabilize. The ball moves freely along the length of the beam. Sensors are placed on one side of the beam to detect the position of the ball. An actuator must drive the beam to a desired angle, either by applying a torque at the center, or in our case, a force at one of the ends.

The physical hardware of the system is simple, a steel ball rolling on the top of a long wooden beam. The beam is mounted on the output shaft of an electrical motor and so the beam can be tilted about its center axis by applying an electrical control signal to the motor amplifier. The position of the ball on the beam can be measured using a special sensor; Figure 2 shows the simple diagram for ball and beam.

When the angle is changed from the horizontal position, gravity causes the ball to roll along the beam. The objective of this paper is to design a digital PID controller using LabVIEW, and DAQ 6024E for this system so that the ball's position can be manipulated.

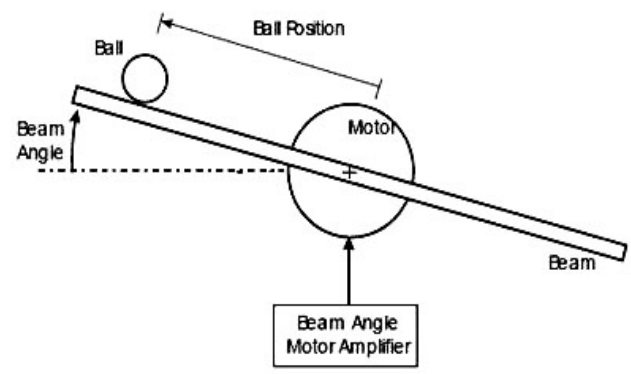

Figure (2): Ball and beam System

\section{DYNAMIC MODEL}

Physical systems are modeled and manipulated in software, and realized in hardware to demonstrate what differences may occur with real-life applications. By solving control problems using software-based virtual instruments 
and actual hardware, students gain an appreciation of the interaction of process instrumentation and computers [1].

The complete description of the dynamics of the ball rolling on the beam is quite complicated and for contro system design a simplified derivation is used to give a model that is good for controller design. The system consists of two motional parts, the beam which rotate with the shaft of the motor, and the rotating ball which roll on the beam according to its angle. Figure (3) describe the behavior of ball and beam system [2].

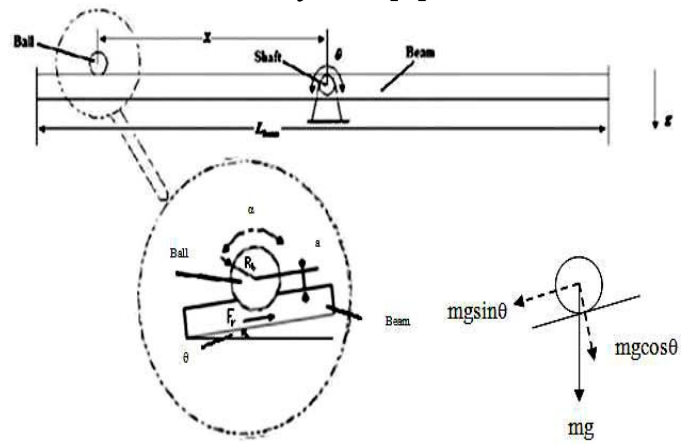

Figure (3): Ball and Beam System and free body diagram of the ball.

\section{A. Rolling ball on the beam equations}

Applicant the motion laws on the ball

$$
\mathrm{m}_{\text {ball }} \mathrm{gsin} \theta-\mathrm{F}_{\mathrm{r}}=\mathrm{m}_{\text {ball }} \mathrm{x}^{\prime \prime}-\mathrm{b}_{1} \mathrm{x}^{\prime}
$$

Where,

- $\quad \mathrm{F}_{\mathrm{r}}$ The rolling constraint force on the ball.

- $\quad b_{1}$ The damping between the ball and the wires (we can neglect it).

- $\quad \mathrm{m}_{\text {ball }}$ The ball mass.

- $\quad$ g The gravity acceleration.

- $\quad \theta$ The angular displacement of the beam.

- $\quad \mathrm{x}$ The displacement of the ball.

\section{B. Electromechanical system Equations}

Applicant the motion laws on the motor and the beam rotation

$$
\begin{aligned}
& \mathrm{KI}-\mathrm{J}_{\mathrm{bm}} \theta^{\prime \prime}-\mathrm{b} \theta^{\prime}-\mathrm{xm}_{\text {ball }} g \cos \theta=0 \\
& \mathrm{~J}_{\mathrm{bm}}=\mathrm{J}_{\text {beam }}+\mathrm{J}_{\text {motor }} \\
& \mathrm{J}_{\text {beam }}=\frac{1}{12} \mathrm{~m}_{\text {beam }} \mathrm{L}_{\text {beam }}^{2}
\end{aligned}
$$

Where,

- J J $\quad$ motor The moment of inertia of the motor.

- Jbeam The moment of inertia of the beam.

- $\quad m_{\text {beam }}$ The beam mass.

- Leam The beam length

The nonlinear state space model of ball and beam is: as shown in equation (5):

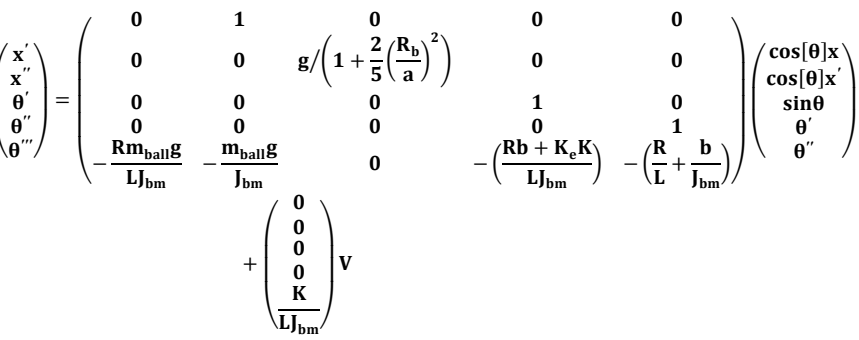

$$
\mathbf{y}=\left(\begin{array}{lllll}
1 & 0 & 0 & 0 & 0 \\
0 & 0 & 1 & 0 & 0
\end{array}\right)\left(\begin{array}{c}
\cos [\theta] \mathbf{x} \\
\cos [\theta] x^{\prime} \\
\sin \theta \\
\theta^{\prime} \\
\theta^{\prime \prime}
\end{array}\right)
$$

A precise mathematical of the ball and beam system is complicated. Fortunately approximate models are sufficient to analyze stability of closed loop system [3]. Now will derive linear approximate model of the ball $\&$ beam system using linearization method. Assume $\theta$ too small, then

$\sin \theta \approx \theta \& \cos \theta=1$, The Linearized model of ball and beam system is a good approximation to real system dynamics. The Linearized model of closed loop system will be as shown in Equation (6)

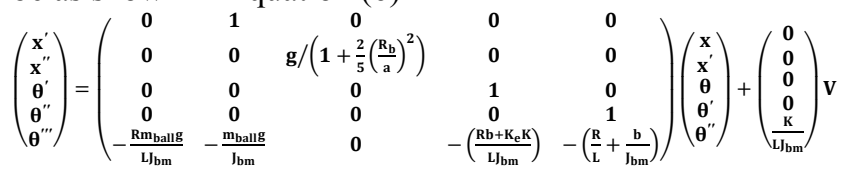

$$
\mathbf{y}=\left(\begin{array}{lllll}
\mathbf{1} & \mathbf{0} & \mathbf{0} & \mathbf{0} & \mathbf{0} \\
\mathbf{0} & \mathbf{0} & \mathbf{1} & \mathbf{0} & \mathbf{0}
\end{array}\right)\left(\begin{array}{c}
\mathbf{x} \\
\mathbf{x}^{\prime} \\
\boldsymbol{\theta} \\
\boldsymbol{\theta}^{\prime} \\
\boldsymbol{\theta}^{\prime \prime}
\end{array}\right)
$$

\section{PID CONTROL}

One of the simplest kinds of controllers is the PID, which stands for proportional-integral-derivative. Each of the three elements is multiplied by its own constant, and then the sum is used to determine the new inputs for the actuator. The mathematical formula for the PID control algorithm is [4, 5]:

$$
u(t)=k_{P} e(t)+k_{I} \int e(t) d t+k_{D} \frac{d e(t)}{d t}
$$

With the correct choice of signs for $K_{\mathrm{P}}, K_{\mathrm{I}}$, and $K_{\mathrm{D}}$, a PID controller as shown in Figure 5 will generate an actuator command that attempts to drive the error to zero with the proportional gain, remove the steady-state error with the integral gain, and dampen the response with the derivative gain. Implementing PID controller to unstable Ball \& Beam will make the closed loop system stable.

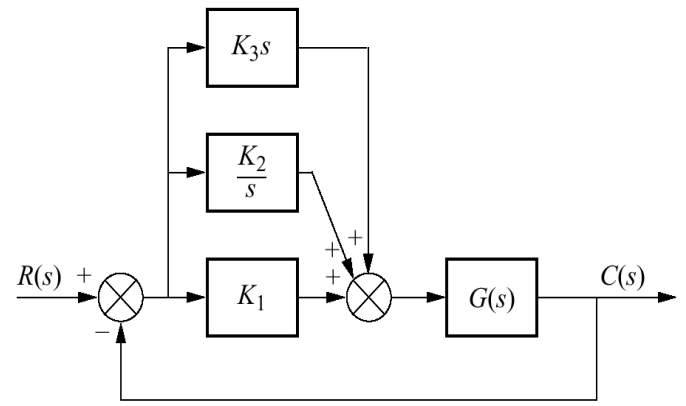


Figure (5): Block diagram of PID controller.

There are many methods available to get the best values of $\mathrm{K}_{\mathrm{p}}, \mathrm{K}_{\mathrm{i}}$, and $\mathrm{K}_{\mathrm{d}}$. One approach is to use a technique that was developed in the 1950's but has stood the time and is still used today. This is known as the Ziegler Nichols tuning method [6].

PID controllers are designed based on LabVIEW program, and the real - time position control of the ball on the beam was realized by using DAQ device.

\section{LABVIEW AND DATA ACQUISITION CARD}

A. LabVIEW (Laboratory Virtual Instrumentation Engineering Workbench) is a graphical programming environment, developed by National Instrument (NI), which is well suited for high-level or system-level design. LabVIEW, developed by National Instruments, is a graphical programming environment suited for high level or system level design. This programming approach is based on building blocks called Virtual Instruments (VIs) [7, 8]. This software package is one of the first graphical programming products, and is currently used in academia and industries for data acquisition, remote control, simulation, and analysis [9]. LabVIEW uses dataflow programming, where the flow of data determines execution. LabVIEW programs are called virtual instruments, or VIs, because their appearance and operation imitate physical instruments, such as oscilloscope and millimeters. Every VI uses functions that manipulate input from the user interface or other sources and display that information or move it to other files or other computers.

\section{A VI contains the following three components [10]:}

- $\quad$ Front Panel: serves as the user interface.

- Block Diagram: contains the graphical source code that defines the functionality of the VI.

- Icon and connector panel.

Front Panel Building the front panel with controls and indicators (Figure 6), that is the interactive input and output terminals of the VI. Controls are knobs, push buttons, dials, and other input devices. Indicators are graphs, LEDs, and other display. Controls simulate instrument input devices and supply data to the block diagram of the VI. Indicators simulate instrument output devices and display data block diagram acquires or generators.

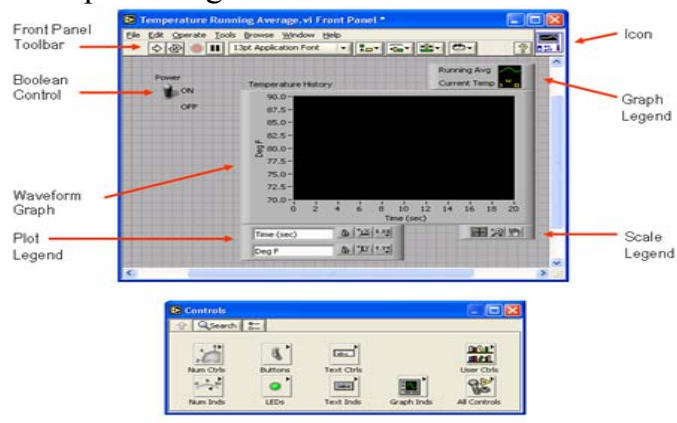

Figure (6): Front Panel and Controls Palette

Block diagram After building the front panel, codes using graphical representation of functions to control the front panel objects. The block diagram contains this graphical source code. Front panel objects appear as terminals on the block diagram.

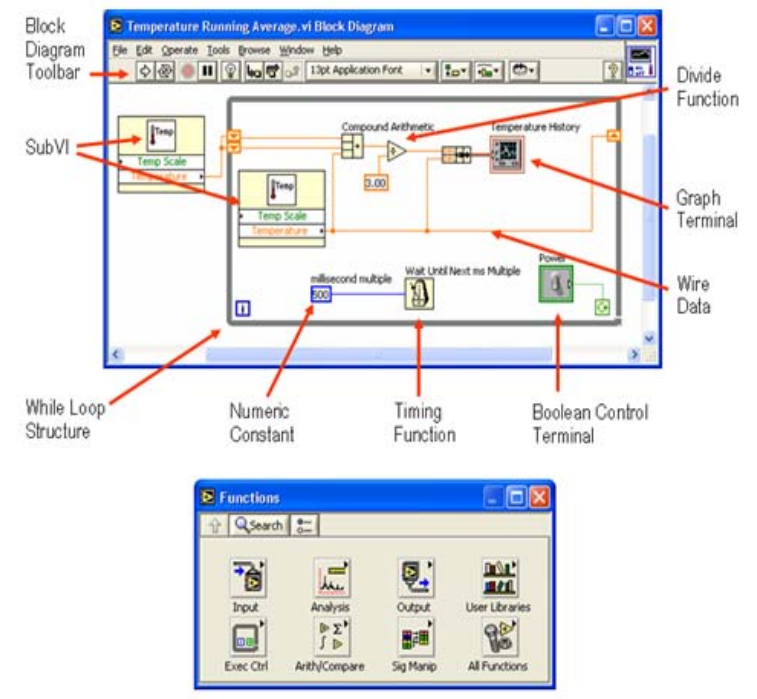

Figure (7): Block Diagram and Functions Palette.

B. Data acquisition is the process by which physical phenomena from the real world are transformed into electrical signals that are measured and converted into a digital format for processing, analysis, and storage by a computer. In a large majority of applications, the data acquisition (DAQ) system is designed not only to acquire data, but to act on it as well. In defining DAQ systems, it is therefore useful to extend this definition to include the control aspects of the total system. Control is the process by which digital control signals from the system hardware are convened to a signal format for use by control devices such as actuators and relays. These devices then control a system or process. Where a system is referred to as a data acquisition system or DAQ system, it is possible that it includes control functions as well.

A data acquisition and control system, built around the power and flexibility of the PC, may consist of a wide variety of diverse hardware building blocks from different equipment manufacturers. It is the task of the system integrator to bring together these individual components into a complete working system.

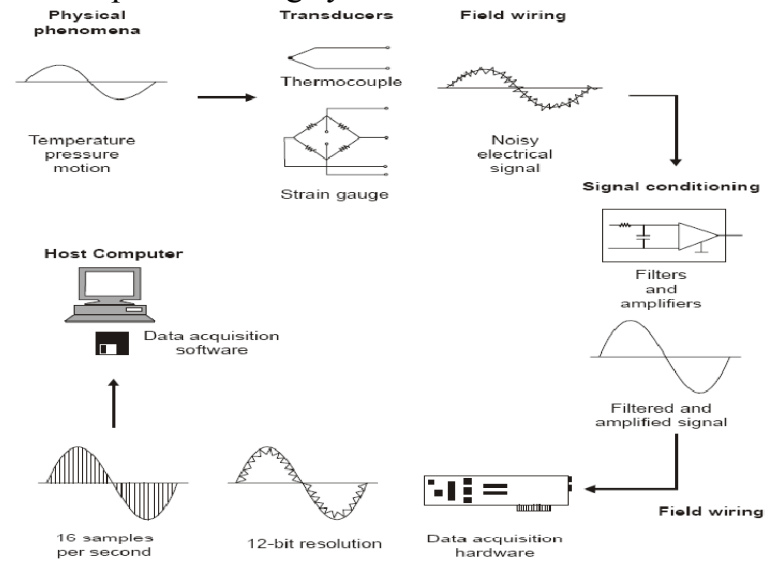

Figure (8): Functional diagram of a PC-based data acquisition system. 
The basic elements of a data acquisition system, as shown in Figure (8), are as follows [11]:

- Sensors and transducers.

- $\quad$ Field wiring.

- Signal conditioning.

- Data acquisition hardware.

- $\quad$ PC (operating system).

- Data acquisition software.

\section{DESIGN AND SimULATION}

\section{Motor and Driver Circuit}

The direction and the torque of the motor are needed to be controlled. In order to meet these requirements, a driver circuit is built which receive low power control signal and turn it to high power to switch the motor. High power Darlington transistor was used to control the torque of the motor by PWM technique. H-bridge circuit (as shown in Figure (17)) was used to control the direction of the motor. Figure (9) show the schematic connection of the driver circuit

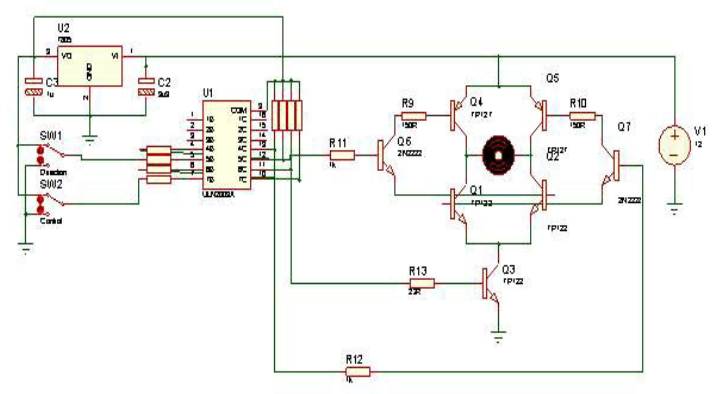

Figure(9): Schematic connection of the driver circuit.

PWM signal was generated using LabVIEW and digital output of the DAQ. Figure 10 shows the programming method to generate PWM. The constant frequency of the PWM $=1 /$ Ts. The value of the duty cycle is changing according to the programmed logical circuit.

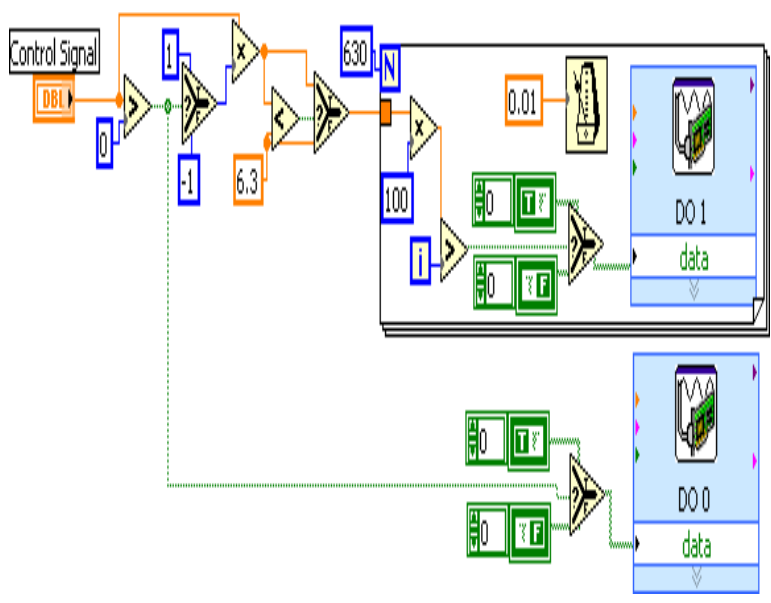

Figure (10): Controlling direction and generating PWM using LabVIEW and DAQ.

Linear resistive wire is used as position sensor since it has a relative large resistance of about $2.15 \mathrm{ohm} / \mathrm{m}$. A series resistor is added to the circuit in order to divide the voltage to avoid unwanted heat. According to the position $(\mathrm{X})$ of the ball, the voltage will linearly vary from $0.1 \mathrm{~V}$ to $0.74 \mathrm{~V}$. Schematic of the resistive wire circuit is shown in Figure (11).

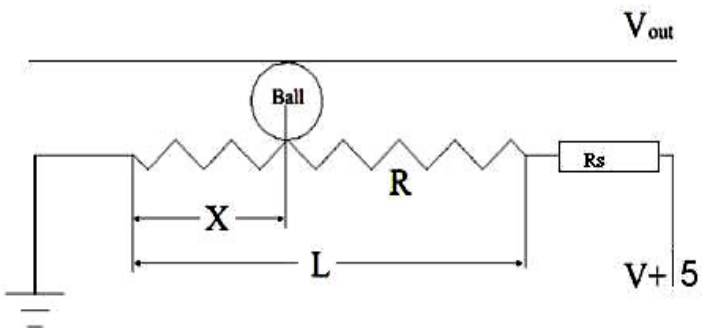

Figure (11): Schematic of the linear resistive wire circuit "position sensor".

It is possible to use the versatile National Instruments counter/timer DAQ card NI-PCI 6024E DAQ device shown in Figure (12) to create a wide variety of measurement solutions, including measuring a number of time-related quantities, counting events or totalizing, and monitoring position with quadrature encoders. You can also use counter/timers to generate pulses and pulse trains. Counter/timers often fulfill critical timing functions as components of complex measurement systems [12]

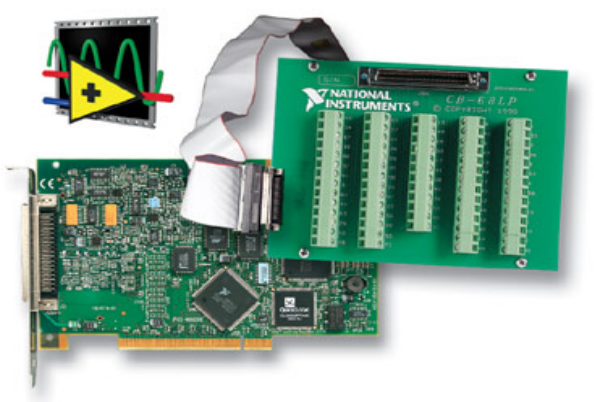

Figure (12): DAQ 6024E and the pin connector

This board uses the National Instruments DAQ-STC system timing controller for time-related functions. The DAQ-STC consists of three timing groups that control analog input, analog output, and general purpose counter/timer functions. These groups include a total of seven 24-bit and three 16-bit counters and a maximum timing resolution of $50 \mathrm{~ns}$. The DAQ-STC makes possible such applications as buffered pulse generation, equivalent time sampling, and seamless changing of the sampling rate.

A linear resistive wire is used as a position sensor and the conductive ball moving along it acting as a voltage divider. By moving the ball along the wire, and taking the reading using the analog input of the DAQ, the result signal has non continuity so it needed filtering. Using low pass filter, we take array of samples every sampling time, and then calculate the average of these samples to make the signal smoother as shown in Figures (13a \& 13b).

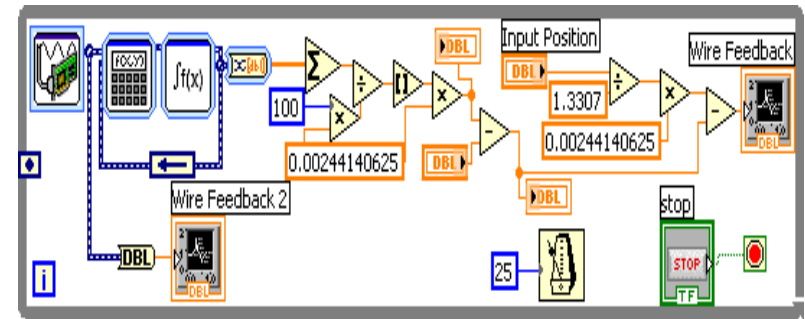


Figure (13a): Before filtering.
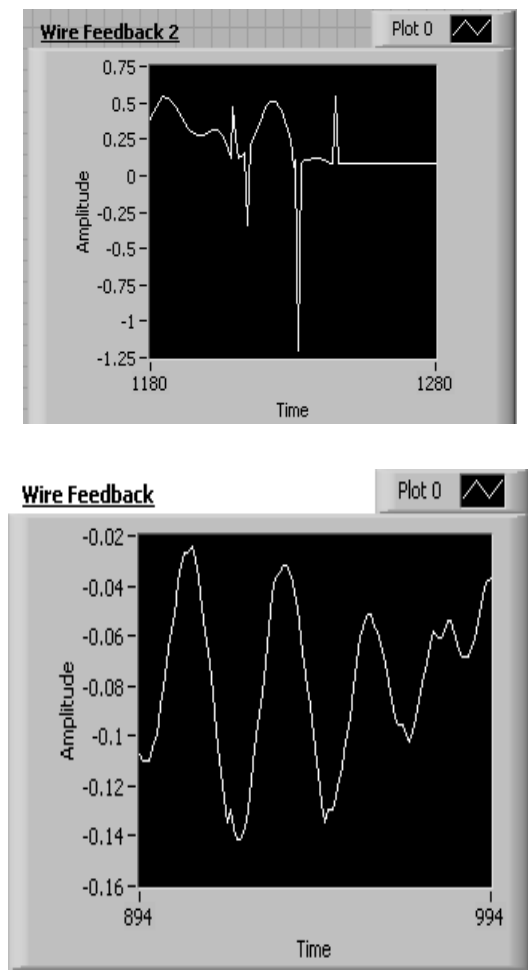

Figure (13b): After Filtering

After handling the feedback signals, the PID controller is ready to be design and gains $\left(K_{\mathrm{P}}=6, K_{\mathrm{I}}=2\right.$, and $\left.K_{\mathrm{D}}=6\right)$ were gotten using Ziegler Nichols tuning method Figure (14, 15) shows the block diagram, and front panel of PID controller respectively.

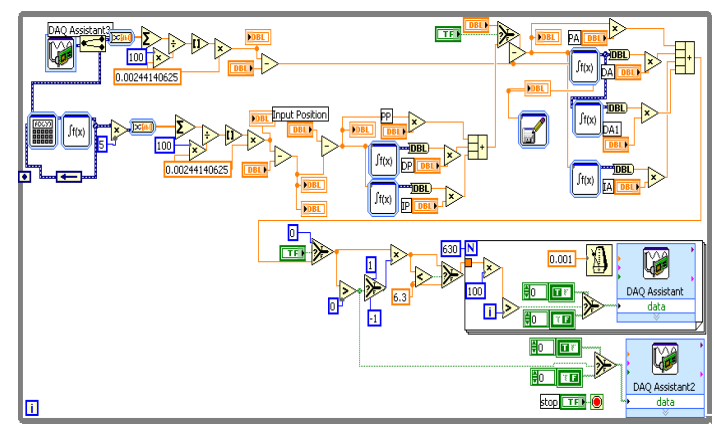

Figure (14): Block diagram of PID controller.
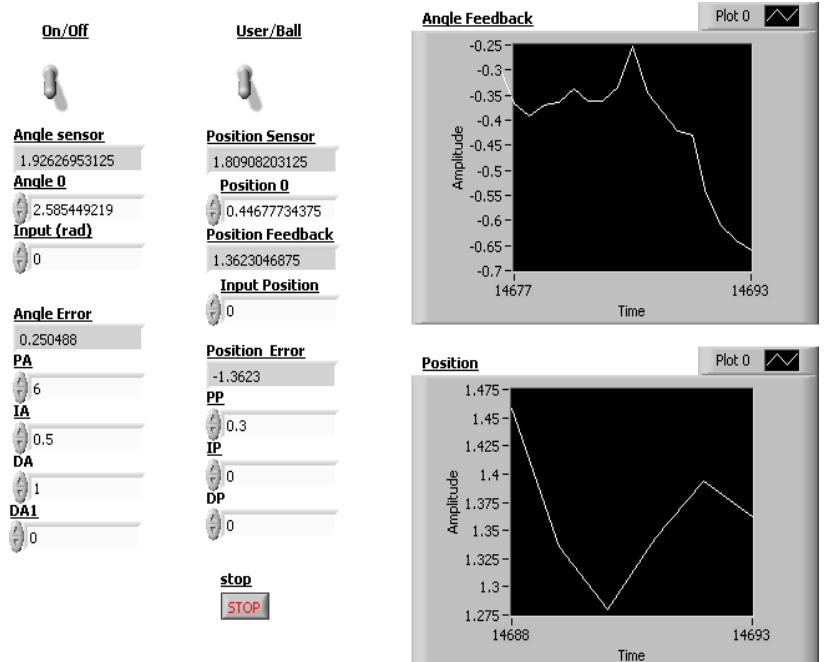

Figure (15): Front panel of PID controller

Figure 15 shows the simulation result of the angle of the beam $(\theta)$ and ball position $(\mathrm{x})$ on the beam. To reach acceptable speed when the ball acts on the beam PID controller is applied to the ball \& beam system. The closedloop response of the ball $\&$ beam system is shown in Figure (16), and the figure shows the system is stable and has small overshoot and zero steady state error.

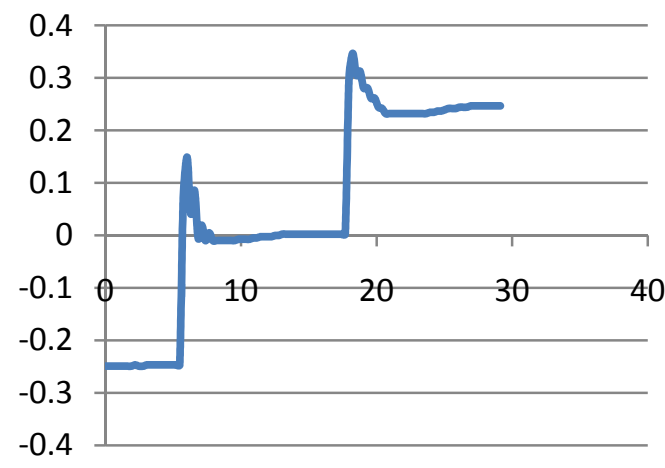

Figure (16): The response angle of the ball on the beam

\section{CONCLUSION}

The LabVIEW based DAQ system is used to control the ball and beam system. DAQ 6024E was used for measuring the feedback signals and converting them into a digital format for processing, analysis, and storage on a computer. To drive the DC motor and control its direction, H-Bridge driver circuit was designed and implemented. PWM was programmed using LabVIEW to control the motor speed. The flexibility of digital control makes it easy to change the gains values without the need of new components. The application of virtual instruments makes data analyzing more accurate, and decreases the measuring time significantly. This system has been used for demonstration in the classroom to the students and the system is stable, and works properly.

\section{REFERENCES}

[1] Elmerabete, J. Hong Li Rafi, Y." Application of Real-Time Control System Using LabVIEW in Distance-Learning” International Conference on Measuring Technology and Mechatronics Automation (ICMTMA), Volume. 1, 2010, 663 - 666

[2] http://www.mecheng.adelaside.edu.au/

Novell/projects/2007/Ball-Beam, October 2008. robotics 
[3] Li Qiu, and Kemin Zhou "Introduction to Feedback Control". 2010, Prentice Hall

[4] Norman S. Nise."Control Systems Engineering", $4^{\text {th }}$ edition. 2004, John Wily \& Sons, Inc.

[5] Benjamin C. Kuo and Farid Golnaraghi, "Automatic Control Systems", $8^{\text {th }}$ edition. 2003 John Wiley \& Sons, Inc.

[6] Tipsuwanpom, Runghimmawn, T Runghim, T. Intajag, and S. Krongratana "Fuzzy logic PID controller based on FPGA for process control," Industrial Electronics, 2004 IEEE International Symposium, Vol.2, No.11, 2004, 1495- 1500

[7] N. Kehtarnavaz, N. Kim, and I. Panahi, Digital signal processing system design using LabVIEW and TMS320C6000, IEEE Digita Signal Processing Workshop, 2004.

[8] Chance Elliott, Vipin Vijayakumar, Wesley Zink, and Richard Hansen:National Instrument LabVIEW: A programming environment for laboratory automation and measurement, The association for Laboratory Automation, 2007.

[9] Korrapati R.; Anderson, J.A; Swain, N.K; Swain M; "System Modeling Using Virtual Instruments" Southeast Con, 2002. Proceedings IEEE Digital Object Identifier:10.1109/.2002.995570 Publication Year: 2002, Page(s): 121 - 126

[10] LabVIEW User Manual, April 2003 Edition, National Instruments

[11] John Park, and Steve Mackay."Practical Data Acquisition for Instrumentation and Control Systems". Copyright (C) 2003, IDC Technologies

[12] National Instruments, DAQ 6023E/6024E/6025E, user manual: January 1999 Edition

Dr. Basil Hamed is Assistant Professor of Electrical Engineering Department, Islamic University of Gaza, Palestine, since 1999. He has Bachelor Degree in Electrical Engineering from New Mexico State University, NM. USA in the year of 1989, he received Master degree from University of New Orleans, La. USA in the year of 1992, and earned his $\mathrm{PhD}$ (Fuzzy Control System) from New Mexico State University, NM. USA in the year 1999. He has 15 years of teaching experience and has published many papers in national and international journals. His fields of interest include Control Systems, Fuzzy Control, Simulation \& Modeling, Signal and Image Processing

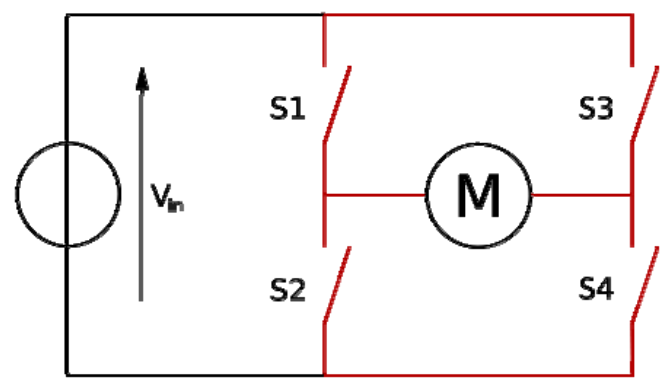

Figure (17): Graphical represitation of H-bridge. '

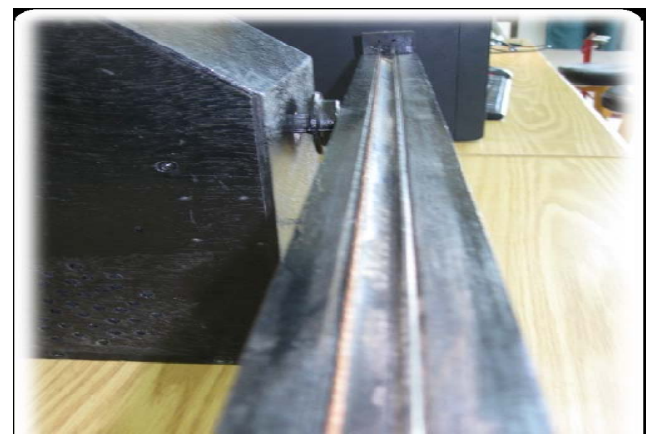

Figure (18): A photograph of linear resistive wire "position sensor"

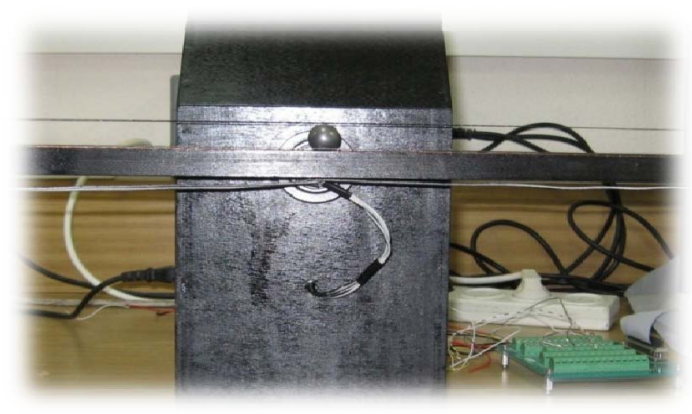

Figure (19): Ball and beam system

\begin{tabular}{|c|c|c|c|l|}
\hline S1 & S2 & S3 & S4 & \multicolumn{1}{|c|}{ Result } \\
\hline 1 & 0 & 0 & 1 & Motor moves right \\
\hline 0 & 1 & 1 & 0 & Motor moves left \\
\hline 0 & 0 & 0 & 0 & Motor free runs \\
\hline 0 & 1 & 0 & 1 & Motor brakes \\
\hline 1 & 0 & 1 & 0 & Motor brakes \\
\hline
\end{tabular}

TABLE 2: THE H-BRIDGE OPERATIONS SUMMARY

\begin{tabular}{|l|l|l|l|}
\hline \multicolumn{1}{|c|}{ Parameter } & \multicolumn{1}{|c|}{ Symbol } & \multicolumn{1}{|c|}{ Value } & \multicolumn{1}{|c|}{ Unit } \\
\hline Mass of ball & $\mathrm{M}_{\text {ball }}$ & 0.03 & $\mathrm{~kg}$ \\
\hline Ball Radius & $\mathrm{R}_{\text {ball }}$ & 0.01 & $\mathrm{~m}$ \\
\hline $\begin{array}{l}\text { Radius of ball } \\
\text { rotation motion }\end{array}$ & $\mathrm{a}$ & 0.00866 & $\mathrm{~m}$ \\
\hline $\begin{array}{l}\text { Mass of the } \\
\text { beam }\end{array}$ & $\mathrm{M}_{\text {beam }}$ & 0.45 & $\mathrm{~kg}$ \\
\hline Beam length & $\mathrm{L}_{\text {beam }}$ & 0.68 & $\mathrm{~m}$ \\
\hline $\begin{array}{l}\text { Friction } \\
\text { constant }\end{array}$ & $\mathrm{b}_{1}$ & $\begin{array}{l}\text { Very } \\
\text { small }\end{array}$ & $\mathrm{Ns} / \mathrm{m}$ \\
\hline $\begin{array}{l}\text { Gravity } \\
\text { acceleration }\end{array}$ & $\mathrm{g}$ & 9.8 & $\mathrm{~m} / \mathrm{s}^{2}$ \\
\hline $\begin{array}{l}\text { Electromotive } \\
\text { force constant }\end{array}$ & $\mathrm{K}$ & 0.08181 & $\mathrm{Nm} / \mathrm{A}$ \\
\hline $\begin{array}{l}\text { Moment of } \\
\text { inertia of the } \\
\text { beam }\end{array}$ & $\mathrm{J}_{\text {beam }}$ & 0.024 & $\mathrm{~kg} \cdot \mathrm{m}^{2}$ \\
\hline $\begin{array}{l}\text { Moment of } \\
\text { inertia of the } \\
\text { motor }\end{array}$ & $\mathrm{J}_{\text {motor }}$ & $1.3625 \mathrm{e}-5$ & $\mathrm{~kg} \cdot \mathrm{m}^{2}$ \\
\hline
\end{tabular}


IACSIT International Journal of Engineering and Technology, Vol.2, No.4, August 2010 ISSN: 1793-8236

\begin{tabular}{|l|l|l|l|}
\hline $\begin{array}{l}\text { Moment of } \\
\text { inertia }\end{array}$ & $\mathrm{J}_{\mathrm{bm}}$ & $\begin{array}{l}24.0136 \mathrm{e}- \\
3\end{array}$ & $\mathrm{~kg} \cdot \mathrm{m}^{2}$ \\
\hline $\begin{array}{l}\text { Resistance of } \\
\text { the motor }\end{array}$ & $\mathrm{R}$ & 2.6995 & $\mathrm{Ohm}$ \\
\hline Motor constant & $\mathrm{Ke}$ & 0.08181 & $\mathrm{volts} /(\mathrm{rad} / \mathrm{s})$ \\
\hline $\begin{array}{l}\text { Inductance of } \\
\text { the motor }\end{array}$ & $\mathrm{L}$ & 0.2412 & $\mathrm{H}$ \\
\hline $\begin{array}{l}\text { Damping ratio } \\
\text { of the motor }\end{array}$ & $\mathrm{b}$ & $1.3625 \mathrm{e}-4$ & $\mathrm{Nm} /(\mathrm{rad} / \mathrm{s})$ \\
\hline
\end{tabular}

TABLE 2: BALL AND BEAM SYSTEM PARAMETERS. 